\title{
OBITUARIO ING. AGRÓN. RAYMUNDO HANSEN DEL ORBES (1943-2020)
}

\author{
In memoriam \\ Ing. Agrón. Raymundo Hansen del Orbes \\ (1943-2020)
}

\section{Omar Paíno Perdomo}

Área de Ciencias Básicas y Ambientales. Instituto Tecnológico de Santo Domingo (INTEC), Santo Domingo. República Dominicana ORCID: 0000-0002-9937-0153, Correo-e: omar.perdomo@intec.edu.do, operdomo92@uasd.edu.do

Cómo citar: Perdomo, O. P. (2021). Obituario. Ing. Agrón. Raymundo Hansen del Orbes (1943-2020). Ciencia, Ambiente y Clima, 4(2), 39-41. Doi: https://doi.org/10.22206/cac.2021.v4i2.pp39-41

El Prof. Hansen nace el 15 de marzo de 1943, siendo el tercero de seis hijos de la unión de Don Eduardo Antonio Hansen Peláez y Doña Ana Dilia Orbes Felipe. Sus estudios primarios y secundarios los realizó en la ciudad de Santo Domingo, en la Escuela Juan Pablo Duarte, actualmente conocida como el Liceo Juan Pablo Duarte, donde se graduó de Bachiller en Ciencias Físicas y Matemáticas. Simultáneamente, durante sus estudios, trabajó como ayudante en el taller de ebanistería de su padre y en el antiguo Supermercado Casa Velázquez.

Al culminar la secundaria ingresó a la Universidad Autónoma de Santo Domingo (UASD) a cursar la carrera de Ingeniería Agronómica en la Facultad de Ciencias Agronómicas y Veterinarias. Durante los primeros años de sus estudios se entusiasma e incursiona en el área de la Botánica junto a varios científicos del área, que eran sus profesores, como el profesor Eugenio de Jesús Marcano, el Padre Julio Cicero, Dr. José de Jesús Jiménez Almonte, entre otros, y con quienes realizó varias exploraciones botánicas en la geografía nacional. Sus colegas coetáneos del cuerpo de docentes de la catedra de Botánica de la Escuela de Biología estuvieron integrados por los maestros Berlina Liria, Manuel Valdez, Ramón Quińonez, Héctor Montes de Oca y Benito Monción.

Realizó estudio de Post Grado en Control de Malezas en cultivos Tropicales en la Universidad de Hohenheim, del estado federado de Baden-Wurtemberg (Stuttgart, Alemania). Antes de iniciar su perfeccionamiento para Alemania en el mes de marzo de 1974 contrae nupcias con la Sra. Dulce María Traboux Tisol, y de este matrimonio se concibieron tres hijos: Alejandro Eduardo, Raysa Dilenia y Raymundo. El círculo familiar estuvo integrado por sus nietos Berliza, Gabriela, Gabriel y Ximena, la cual no conoció.

$\mathrm{Al}$ regresar de Europa, inicia su carrera de docente en el departamento de Biología de la Facultad de Ciencias. Fue encargado del departamento de Sanidad Vegetal de la Secretaría de Estado Agricultura (Ministerio de Agricultura) en la sede de la provincia San Cristóbal. Además, laboró en empresas privada como Fertilizantes Santo Domingo (Fersan), American Cianamyd Company y AgroFarma, desarrollando un sinnúmero de tratamientos para el control de malezas 
y enfermedades en cultivos de arroz, cacao, tabaco, banano entre otros.

Los últimos años de su vida fue asesor de tesis, consultor y se dedicó a impartir docencia en el Instituto Politécnico Loyola desde el 1998 y perteneció a la Unidad de Biotecnología de la Facultad de Ciencias Agronómicas y Veterinarias de la Universidad Autónoma de Santo Domingo (UASD).
Muchos de quienes lo conocimos estamos agradecidos por sus enseñanzas y reconocemos sus contribuciones en la agronomía y la herbología. Ciertamente su ausencia deja un gran vacío, pero también hereda un gran legado a todos los nuevos profesionales que formó y a sus sucesores. Agradezco a la familia Hansen por facilitarme información, material fotográfico y asumo la responsabilidad por cualquier omisión o interpretación de esta necrología.

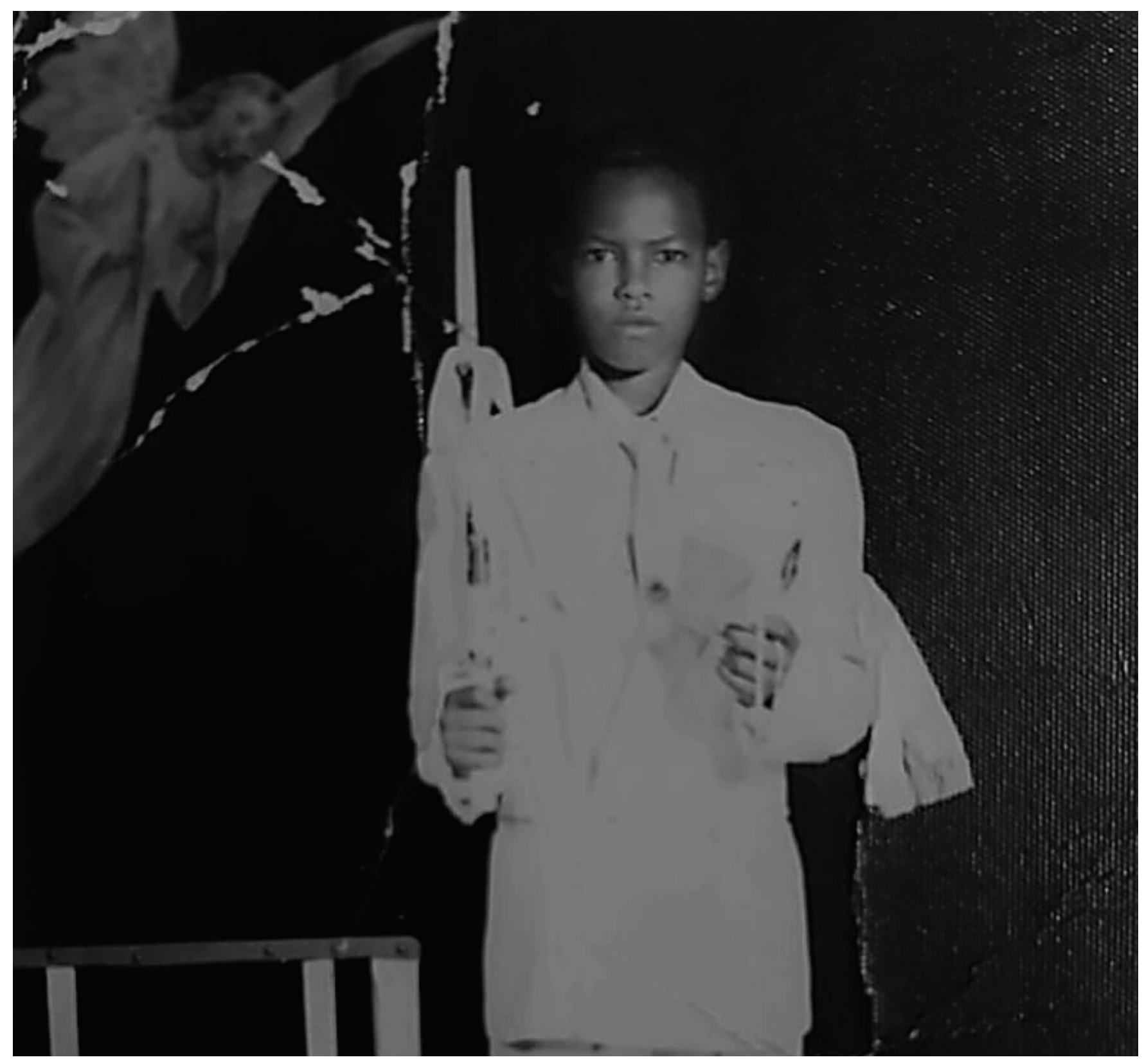

Foto 1. Infancia de Raymundo Hansen del Orbes. 15 años de edad. 


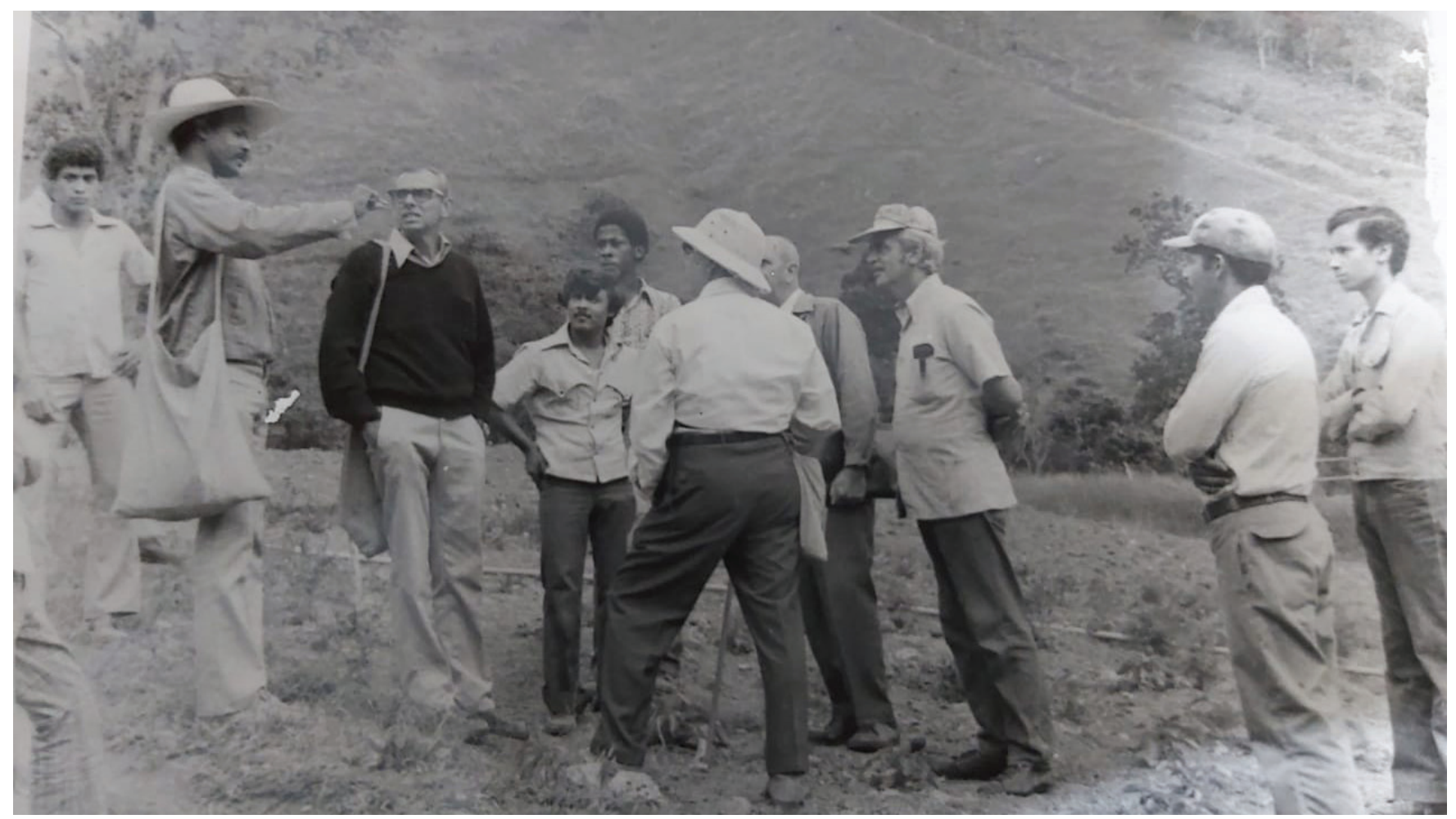

Foto 2. Raymundo Hansen del Orbes, en exploración botánica junto a los profesores Julio Cicero, Eugenio de Jesús Marcano y otros colegas.

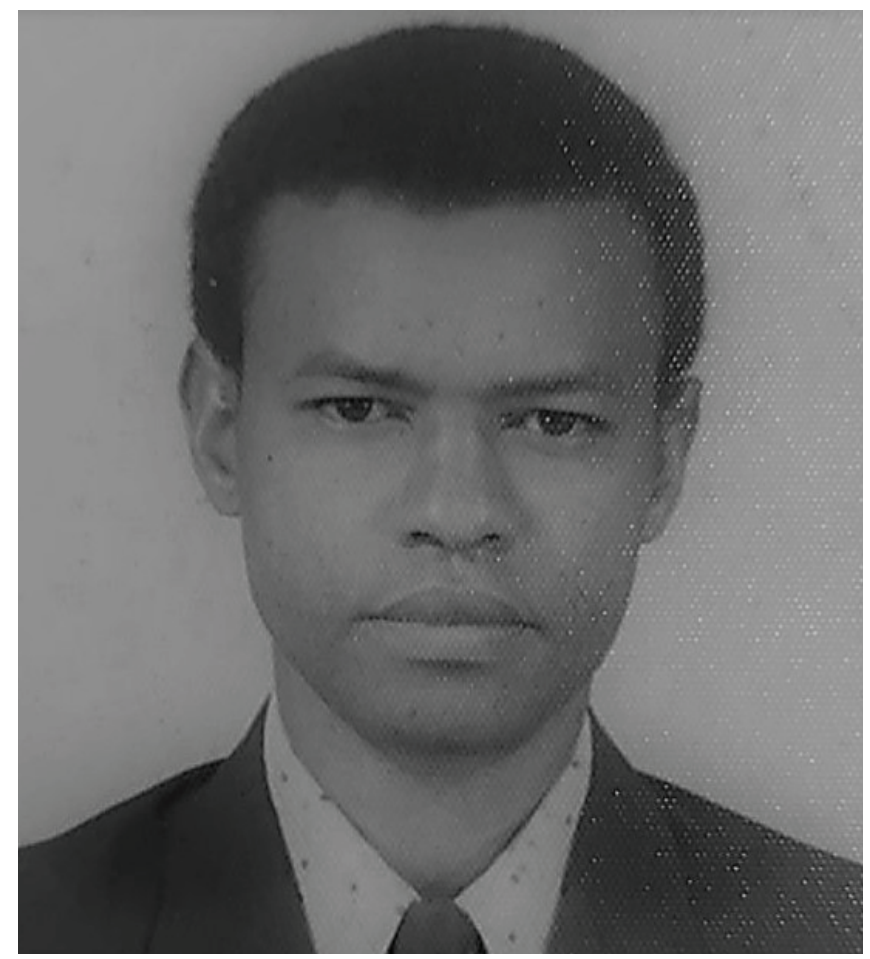

Foto 3. Raymundo Hansen del Orbes. 30 ańos de edad.

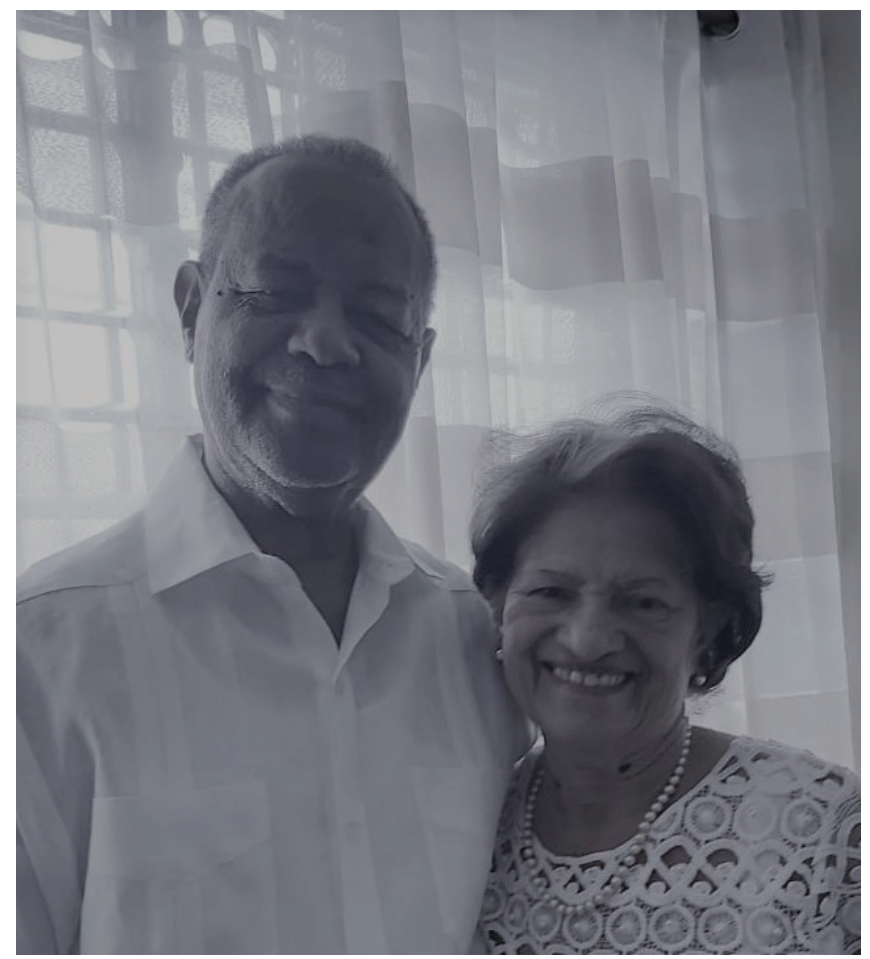

Foto 4. Raymundo Hansen del Orbes y Dulce María Traboux Tisol. 